\title{
ON THE FORM OF THE SPLEEN AND THE KIDNEYS.
}

\author{
Br D. J. CUNNINGHAM, M.D., D.C.L. (Oxon), F.R.S.; \\ Professor of Anatomy, University of Dublin.
}

[Read in the Section of Anatomy and Physiology, May 31, 1895.]

Two methods have been adopted by anatomists with the view of obtaining an accurate knowledge of the true form of the solid viscera of the abdomen. By the first of these the organs are hardened in situ by an injection of from five to ten litres of a $\frac{1}{2}$ per cent. or a 1 per cent. solution of chromic acid under a given pressure. This is the method which was employed by Professor His ${ }^{\mathrm{a}}$ in the preparation of his now celebrated models, the production of which has, in many respects, revolutionised our ideas upon the topographical anatomy of the abdomen.

By the second method the organs are built up by a process of reconstruction. A suitable subject having been selected, it is in the first instance frozen. The trunk is then divided by means of a saw in the sagittal direction into eight slabs of nearly equal thickness by seven sections. The slabs thus obtained are hardened, care being taken to insure a uniform shrinkage of the different viscera. When the necessary consistence is attained the different pieces of a given organ are removed from each slab in turn, cast in plaster of Paris, and then modelled in soft wood. When the various parts are completed they are fitted together, and the organ is thus

- Wilhelm His. Über Präparate zum Situs Viscerum mit besonderen Bemerkungen über die Form und Lage der Leber, des Pancreas, der Nieren und Nebennieren sowie der weiblichen Beckenorgane. Arch. $f$. Anat. und Entwick. 1873. P. 53. 
reconstructed. It is obvious that this method is calculated to give very accurate results, although it is also evident that a source of error is apt to creep in through the loss of substance produced by the various saw-cuts. The amount of this loss, however, can be estimated, and in the wooden models added to both surfaces of the different pieces of a given organ. One marked advantage which the reconstruction method possesses consists in the fact that by the lines of union of the separate pieces we obtain very accurate information regarding the topography of an organ so reconstructed, seeing that the sections are nade along certain well-established planes.

Of course the great disadvantage of the reconstruction method is the immense amount of labour which it involves. For my own part I may say that it would have been impossible

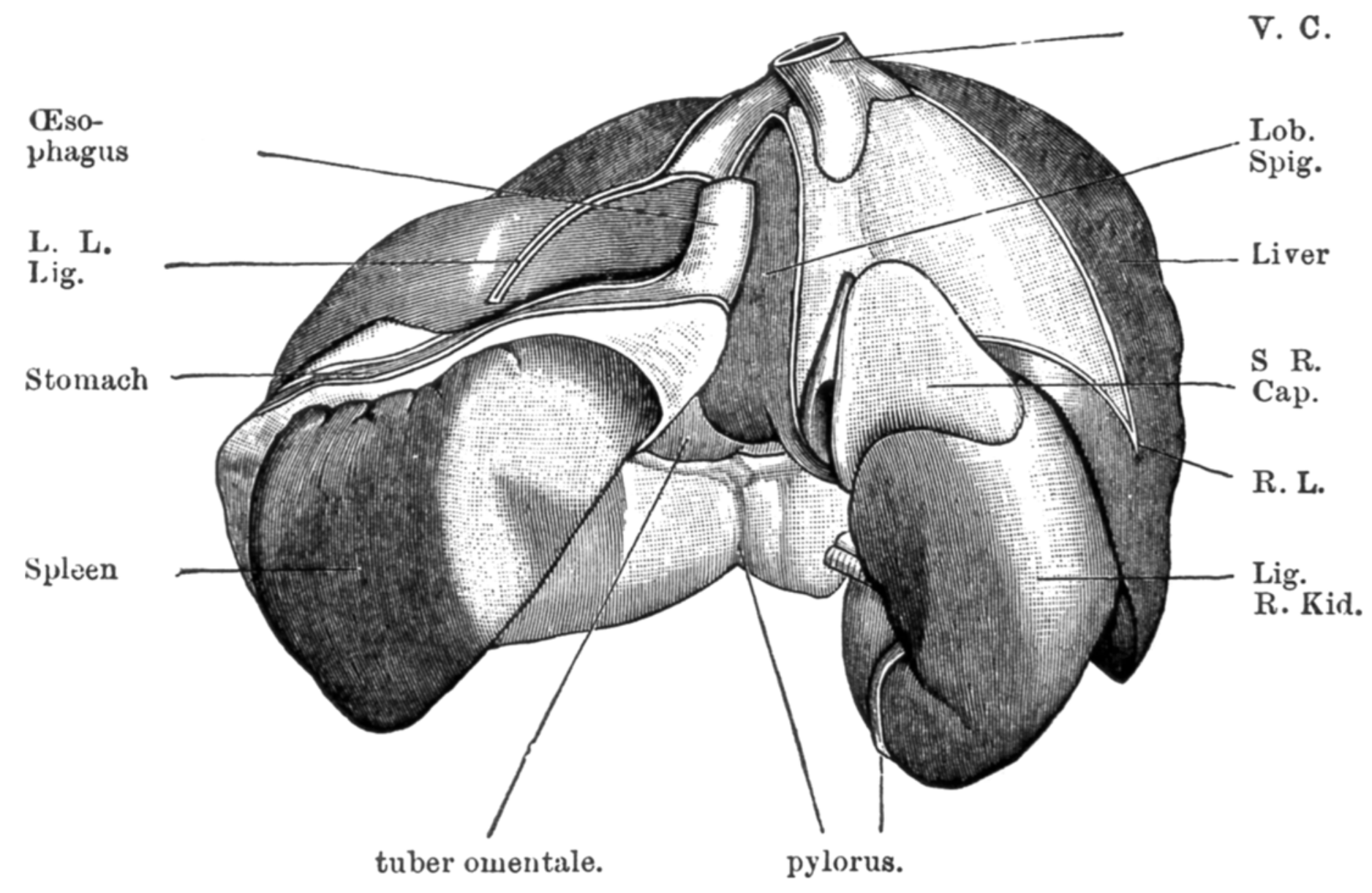

Fra. 1.-Model, produced by the reconstruction method, of the liver, right kidney, stomach, and spleen of a child.

for me to have undertaken it had it not been for the assistance which I have obtained from my working assistant, Mr. John Stirling, who is a trained and exceptionally skilful woodcarver. In conjunction with him I have reconstructed the 
liver of an adult male, and the liver, stomach, kidneys, and spleen of a female child. This work was completed about two years ago, and the originals were placed in the hands of Messrs. Casciani \& Co., in order that they might supply duplicates to those anatomists who might desire to have them. The form, however, which was obtained for the kidneys, and more especially for the spleen, differed so markedly from that exhibited by the models of these organs produced by Professor His that I was unwilling to publish my results until I was assured that I was not dealing with individual peculiarities.

During the last few months I have had an opportunity of checking my results by the injection method. In all I have hardened three adult subjects-two well-formed females and one male. In the first two of these I employed Müller's fluid followed by graduated spirit injections. In the case of one of the subjects (A) the injections were repeated almost daily for a period of two weeks, whilst in the other (B) the hardening process was continued for fully six weeks. The third subject, at the suggestion of my assistant, Dr. A.F. Dixon, I injected with a saturated solution of chloride of zinc followed by spirit, but although this method in his hands has afforded excellent results in the case of the advanced fotus, it was found unsuitable for the larger organs of the adult. The viscera which I have obtained from these specially-prepared subjects have satisfied me that our present description of the pancreas, spleen, and kidneys requires some modification, and that the models which had been obtained by the reconstruction method exhibit what may be considered to be the natural form of the organs.

On the present occasion I do not intend referring to the pancreas except incidentally. A few months ago Professor Symington read a paper before the Anatomical Section of the Royal Academy of Medicine in Ireland upon the form 
of this organ. ${ }^{\mathrm{a}}$ The remarks which he then made I can corroborate in nearly every particular. Professor Birmingham has also given some attention to this matter, and I understand that it is his intention to publish shortly some additional observations on the pancreas. His results, so far as I know them from conversation with him, also agree with what I have noted in the course of my investigation.

The two livers which I have reconstructed show many interesting points from the fact that they present two extremes in the changes of form to which this organ is subject from the modelling effect of surrounding viscera; one was obtained from an emaciated adult male, in which the hollow viscera were absolutely empty and the anterior abdominal wall greatly retracted. The organ is flattened from before backwards to such an extent that its inferior surface is almost brought to lie in the same plane as the posterior surface.

'The model of the child's liver presents just the opposite condition. The colon was greatly distended and had exercised a strong pressure in an upward direction upon the stomach and the liver. The vertical depth of the liver is thus greatly reduced, and the different surfaces of the organ are all marked off from each other with the greatest precision. The slight modification of Professor His's description proposed by Professor Symington is therefore particularly applicable to this form of liver. ${ }^{b}$

It is to the form of the spleen and kidneys, however, that I desire specially to call attention in this communication.

Spleen.-Professor His, in the article already quoted, makes very brief reference to the spleen. He alludes to Luschka's account of the organ, and merely remarks that "the adaptation of the spleen to neighbouring viscera is known, and by

- This paper will be found at page 434 .

b Johnson Symington. On certain Physiological Variations in the Shape and Position of the Liver. Trans. Med. Chir. Soc. Edin. 1887. 
the designation of its three surfaces as superficies gastrica, superficies renalis, and superficies phrenica, sufficiently indicated." We are therefore obliged to turn to his model of the organ to obtain an idea as to the conception he has arrived at regarding its form. This model has been very generally taken as a type, and the majority of our descriptions

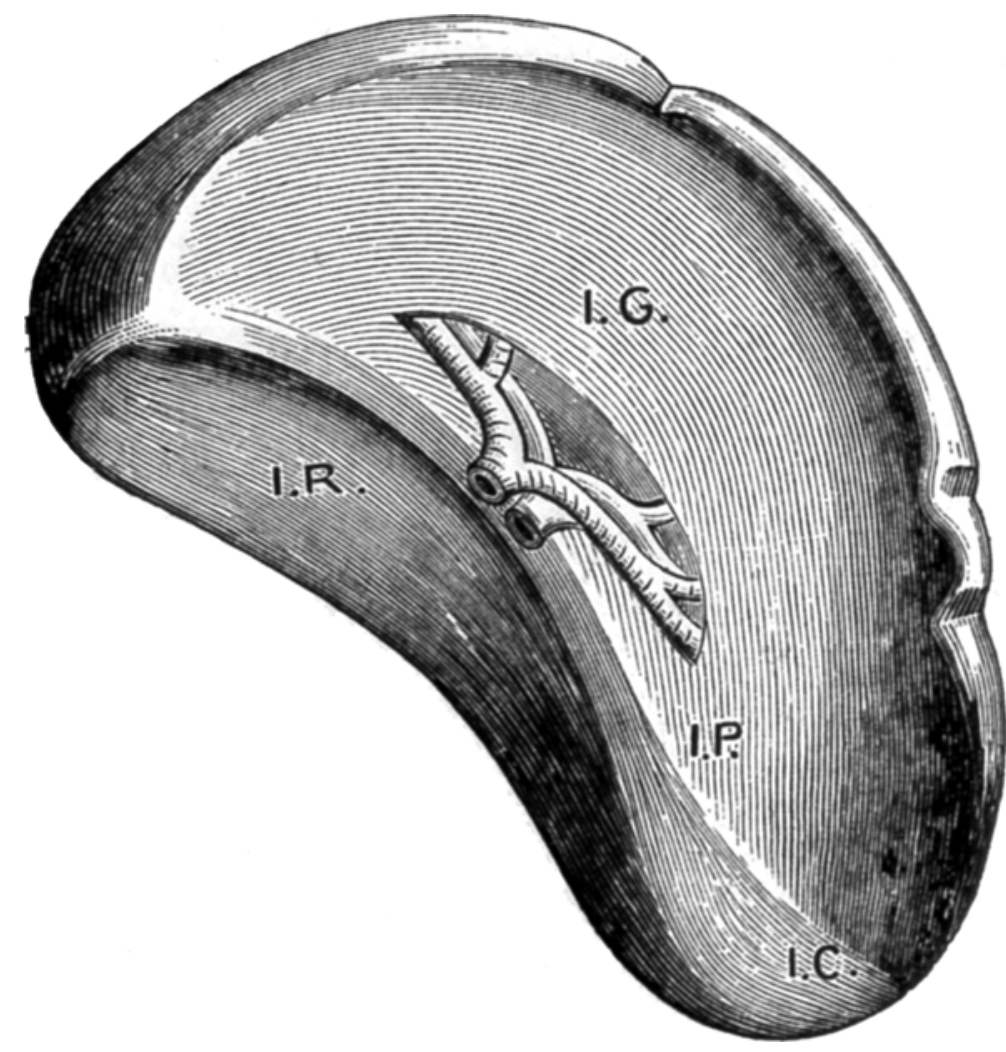

Fig. 2.-From the model of the Spleen, by Professor His. I.G., superficies gastrica: I.R., superficies renalis; I.P., area of contact with pancreas ; I.C., superficies colica.

of the spleen have been framed from it. It represents the spleen as an oval organ, narrower at its lower than at its upper end, and with both of these extremities somewhat pointed. Its visceral aspect is divided by a salient ridge into an anterior gastric concavity which is adapted to the fundus of the stomach, and a posterior deeply hollowed out narrow renal surface which fits closely upon the convex outer margin of the kidney. The tail of the pancreas is in apposition with the lower part of the gastric concavity, but there is no impression on the spleen to mark the place of contact. The lower end of the spleen rests upon the summit of the splenic flexure of the colon.

I have not met with this form of spleen in any of the 
suljects I have specially prepared in the prosecution of this investigation, and whilst I would be slow to insist that such a form does not exist, $I$ have no hesitation in saying that it is not the usual nor is it the typical form of the spleen.

The spleen has the shape of an irregular tetrahedron, with its apex above and its base below. The upper extremity, which may be regarded as representing the apex, is directed inwards and upwards. It is curved to some extent forwards in itself, and not infrequently it exhibits a slight spiral twist in an outward direction. Of the four surfaces the most extensive is the superficies plrenica, which is adapted to the concavity of the diaphragm, and which, as Luschka has pointed out, corresponds in position to the 9 th, 10 th, and 11th ribs. The remaining three surfaces are turned towards the cavity of the abdomen, and are closely applied to the neighbouring viscera. These three surfaces meet at a blunt, but usually very conspicuous prominence, which may be termed the internal basal angle. From this, as from a centre, three ridges radiate. One salient and prominent (the margo intermedius of Luschka) ascends to the apex or upper extremity, and separates the gastric from the renal surface; a second short ridge passes backwards to the posterior basal angle, and intervenes between the renal and the basal surfaces; whilst the third ridge, less distinctly marked, proceeds forwards to the anterior basal angle, and separates the gastric and the basal surfaces from each other. The two lastmentioned ridges, together with the lower border of the organ, map out a very evident triangular area, which may be distinguished as the basal surface (superficies basalis).

The gastric surface (superficies gastrica) is deeply concave, and is moulded upon the fundus of the stomach. Within its area, about half an inch to the outer side of the margo intermedius, is situated the hilum of the spleen. The renal surface (superficies renalis) is not concave, as a rule, but flat and 
even. It varies considerably in extent, and is applied to the anterior surface of the upper part of the kidney, close to its outer border. 'The basal surface is smaller than the other two visceral surfaces. It looks downwards and inwards, and it has the tail of the pancreas as a constant relation. The area of contact with the pancreas is subject to considerable variation, and in many cases a marked pancreatic depression may be observed on the spleen. The pancreas stretches across the front of the left kidney, and supports the base of the spleen in a shelf-like manner. As is well known, the

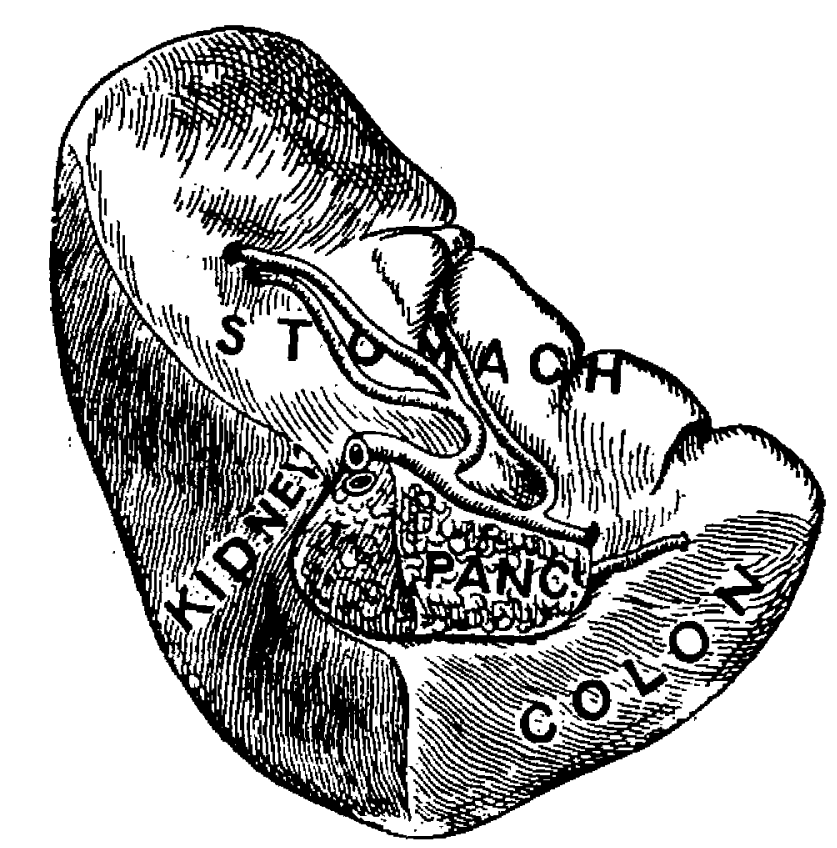

Fia. 3.-From the model of the spleen of a child, obtained by the reconstruction method. It exhibits the typical form of the spleen.

tail of the pancreas does not present an equal development in all subjects. In cases where it is well marked it is folded backwards upon itself, as it lies in relation to the base of the spleen, and may even reach the lateral wall of the abdomen at the level of the 11 th rib. The portion of the basal surface of the spleen which is not in apposition with the pancreas presents a varying relation to the colon.

The anterior border (margo crenatus of Luschka) and the posterior border (margo obtusus of Luschka) of the spleen call for no special remark, but it should be noted that the organ presents a well-marked lower border, which stretches from the posterior to the anterior basal angle, and intervenes 
between the basal visceral surface and external phrenic surface. A very characteristic feature of the typically formed spleen is the great prominence of the anterior basal angle. This constitutes a striking projection, which appears to be more strongly marked in the fotus than in the adult. Luschka calls attention to it, and speaks of it as the "spitzer Winkel" of the lower end of the spleen. It forms the most anteriorly placed part of the organ.

There is abundant evidence to show that the form of spleen which I have described is the true and natural form. It is the shape which I obtained in the model produced by reconstruction, and also in each of the subjects which were specially hardened. Dr. A. F. Dixon has also observed precisely the same shape of spleen (but in a more decided form) in three advanced fotuses (Plate, Fig. 1). But the morphological evidence is still more conclusive. In the Bonnet monkey (Plate, Fig 2) and the baboon the tetrahedral form of the spleen is most marked. The same surfaces, as in the human spleen, can be detected, but these are narrower, and the organ tapers more rapidly towards the upper end. In the orang all the markings present in the human spleen can be detected, and the general outline is very much the same. ${ }^{a}$

But there is another aspect of the question which is not without interest. My assistant, Dr. A. F. Dixon, in discussing the matter with me, pointed out that when an organ is packed into a more or less spherical cavity it will occupy the smallest amount of space consistent with its bulk if it assumes the tetrahedral form. If we regard the spleen from this point of view, then we must look upon the diaphragmatic

${ }^{a}$ It is right to state that I have only had an opportunity of examining the spleen of one orang, and this was enlarged and in a pathological condition. Still its general resemblance to the human spleen was most marked. In the chimpanzee the spleen is very long and narrow, and resembles, in this respect, the same organ in the baboon. It is, however, distinctly tetrahedral in form. 
surface as representing the mathematical base and the socalled internal basal angle, as where the three visceral surfaces meet as the apex of the tetrahedron.

But it may be asked: In the many figures of the spleen which have been published are there none that represent the organ correctly? When we examine a number of text-books of anatomy, it is, indeed, as interesting as it is remarkable to note the many different and sometimes extraordinary shapes which the spleen is made to assume. The only author, so far as I am aware, who gives a satisfactory figure is Luschka. ${ }^{b}$ It is true that his description differs from mine, but then he looks at the organ from a different point of view.

It is right also that $I$ should refer to a very beautiful model which I have received from my friend Dr. Goubaroff, of the Anatomical Department of the University of Moscow. This represents the under surface of the diaphragm and the posterior wall of the abdomen after the removal of the stomach and intestine. It is the most exact and instructive model of the kind with which I am acquainted. In this, the form of the spleen is seen to be precisely the same as that which I have obtained in my specimens; and further, the relation of the pancreas and the backward fold of its tail are exhibited with great accuracy.

Kidneys.-Prior to the publication of Prof. His's article, the majority of anatomists were content in describing the kidney, to call attention to its general bean-shaped form, and to point out that while both surfaces are convex the anterior is fuller and more rounded than the posterior. Some, indeedas, for example, Luschka-have asserted that surrounding

- Professor His has called attention to the fact that the figure of the liver given by Vesalius is in some respects more accurate than many more modern illustrations of that organ. The same might be said with still greater force with regard to the spleen.

- Hubert Luschka. Die anatomie des Menschlichen Bauches. 1863. P. 269. 
organs exert little or no influence in modifying its form. Professor His, who has done so much to give us correct views regarding visceral anatomy, rightly insists that when the kidneys are hardened in situ it is not difficult to prove that such a moulding influence does take place, and he especially refers to the impressions which are produced on the surfaces of these organs by the quadratus lumborum, the psoas, the stomach, the colon, and the liver. It appears to me, however, that the form of kidney which he describes is not a very usual one, and, further, that the models which illustrate his description are not in every respect satisfactory.

The kidneys present many slight changes in form according to the anount and the kind of pressure which is exerted upon them by contiguous viscera. In every case, however, and on both sides, there is, on the anterior surface, a point of maximum convexity-a place where the kidney substance is raised in the form of a marked prominence or bulging, which may slowly rise from all sides to a blunt summit, as is usually the case in the left kidney, or which may extend across the anterior surface in the form of a rounded ridge, as happens more conmonly in the case of the right kidney. A bove and below this eminence the anterior surface falls away towards each extremity in the form of an inclined or sloping plane of greater or less obliquity. These impressed districts indicate pressure exercised on the anterior surface of the kidney in two directions, and the intervening eminence is the result of this pressure and counter-pressure.

Upon the upper inclined plane of the anterior surface of the left kidney is placed the supra-renal capsule, the stomach, and the spleen (Plate, Figs. 4 and 8). These exercise a downward and a backward pressure chiefly through changes in the condition of the stomach, although, no doubt, the diaphragmatic movements produce an indirect influence through both the stomach and the spleen. Upon the inferior 
inclined surface of the left kidney the counter-pressure is produced by the intestinal canal, which presses, as a rule, upwards and backwards.

When a number of specimens are examined, it becomes apparent that the position of the intervening eminence or anterior bulging of the left kidney is not always the same. This, to some extent, may be due to the slightly different position on the posterior wall of the abdomen which the organ holds in different individuals, but without doubt it is also due to the different degrees of gastric and intestinal pressure to which the organ is subjected at different times in the same individual.

On the right side the upper inclined surface is occupied by the liver, whilst in contact with the lower inclined area is the colon (Plate, Fig. 7). Here also there may be observed considerable differences in the extent of these areas, and consequently also in the position of the elevated portion of kidney surface which intervenes between them. Leaving out of sight the variations in the position of the kidney in different individuals, these alterations in the extent of the sloping surfaces on the anterior surface of the right kidney are brought about by the changing conditions of the colon, which presses on the kidney in an upward and backward direction. To this pressure the liver can only offer a more or less passive resistance, except perhaps in the case of the slight influence which it conveys in a downward direction from the diaphragm, and in a backward direction from the anterior abdominal wall.

This pressure and counter-pressure, which produces so constant and so marked a conformation of the anterior surface of the two kidneys, must also exercise an important influence in maintaining the organ in its place, and securing it in that part of the abdominal cavity in which it lies.

In speaking of the areas on the anterior surface of each 
kidney, I have used the term "inclined plane." This must not be interpreted too literally, because the districts in question are not by any means perfectly flat and even, and the term has been used merely with the view of giving forcible expression to the fact that there is a general slope from a central prominence in an upward and downward direction on this aspect of the kidney.

We shall now examine these sloping surfaces in somewhat greater detail. As already stated, the supra-renal capsule, the spleen, and the stomach are in contact with the upper inclined area on the anterior surface of the left kidney. The supra-renal capsule, as a rule, occupies a narrow district along the inner border from the level of the hilum to the summit of the organ. The spleen is in contact over an area immediately adjoining the outer convex border. The extent of this splenic field is variable-varying not only with the breadth of the renal surface on the spleen, but also with the level which is occupied by the kidney in the abdominal cavity. In some cases the surface of contact does not extend downwards lower than one-third of the length of the kidney (Plate, Fig. 4), but in two cases I have observed it reaching down for at least two thirds of the kidney length (Plate, Fig. 8). As a rule, the spleen produces a marked impression, so that when the kidney is well hardened in situ, there is no difficulty in tracing the limits of the splenic contact on the anterior surface. As already mentioned, the models of Professor His show the spleen in contact with the kidney along the outer margin of the latter organ. I have never seen such a relationship.

The pancreas stretches across the left kidney, either immediately above or perhaps exactly over the eminence which intervenes between the two sloping surfaces on the anterior aspect of the kidney, and the area which it occupies is not unfrequently indicated by a faint impression. The supra-renal 
capsule, the spleen, and the pancreas cover, as a rule, the greater part of the upper inclined surface, so that only a small triangular interval is left between them, where direct contact between stomach and kidney takes plice. The extent of this gastric district varies greatly, but it is, as a rule, considerably smaller than is generally supposed, and I have not observed upon it that concavity reierred to by Professor Ifis. In the

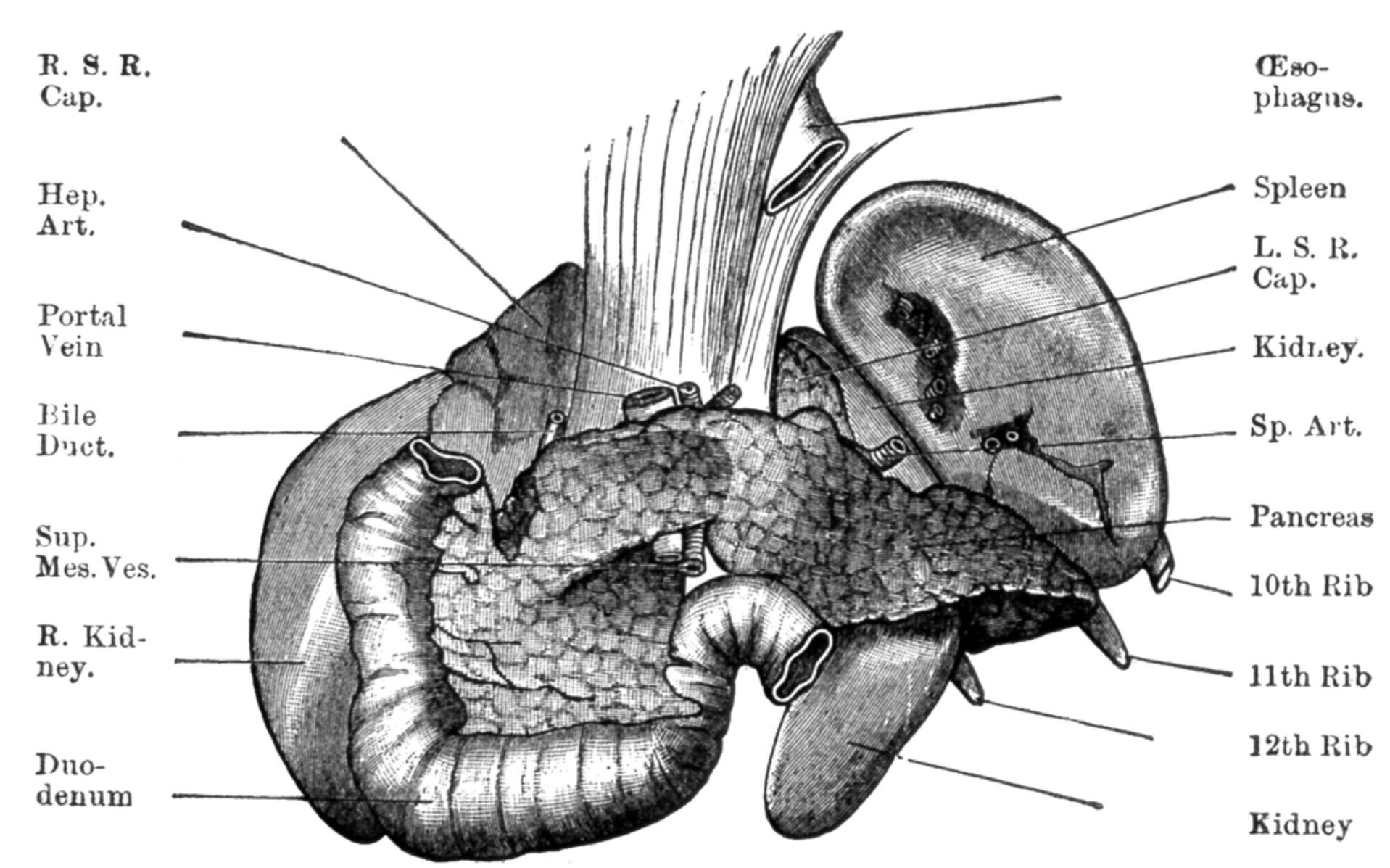

Fra. 4.-Relations of the kidneys as seen in Female Subject B.

reconstructed left kidney of the child the stomach is crowded out altogether by a downward and backward shifting of the supra-renal capsule, and by the great extent of the splenic contact. But these conditions make no difference, in so far as the pressure influence which the stomach exercises upon the upper sloping surface of the kidney is concerned, seeing that the stomach rests upon those organs which are applied to this portion of the kidney, and, as it distends, it presses through them upon the latter organ.

The inferior sloping surface on the anterior aspect of the left kidney has a varying relation to the intestinal canal. 
The colon and, as a rule, some coils of the small intestine are in contact with it.

In the case of the right kidney the colic and hepatic impressions are usually very strongly marked, and in many cases the colic or inferior sloping surface presents a high degree of obliquity. The relation of the duodenum is a very variable one, but as I have discussed this point in a previous paper, it is not necessary to re-open the question. When the duodenum rests upon the kidney (which it almost invariably does), it gives rise to a very evident duodenal impression.

The outer convex border of kidney of both sides presents a marked thickening opposite the eminence on the anterior surface. From this it narrows in an upward and downward direction towards each extremity (Plate, Figs. 5 and 6). Somewhere in the neighbourhood of this marginal thickening a faint groove indicates the place where the border of the kidney is clasped by the last rib. It is interesting to note how smoothly and evenly the curved surface of the posterior aspect of the liver merges into the curvature of the outer border of the right kidney (Fig. 1, p. 441). It would therefore be absolutely impossible to tell by percussion where the one begins and the other ends.

In discussing the characters presented by the posterior surface of the kidney, it is necessary to bear in mind that these undergo considerable modification in accordance with the different levels at which the organ is placed on the two sides and in different individuals. I have constructed the following table from the material at my disposal, with the view of forming some estimate of the extent of this variation in the topography of the kidney:- 


\section{The Form of the Spleen and Kidneys.}

\begin{tabular}{|c|c|c|c|c|}
\hline & 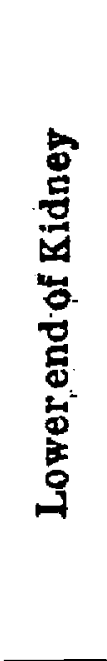 & 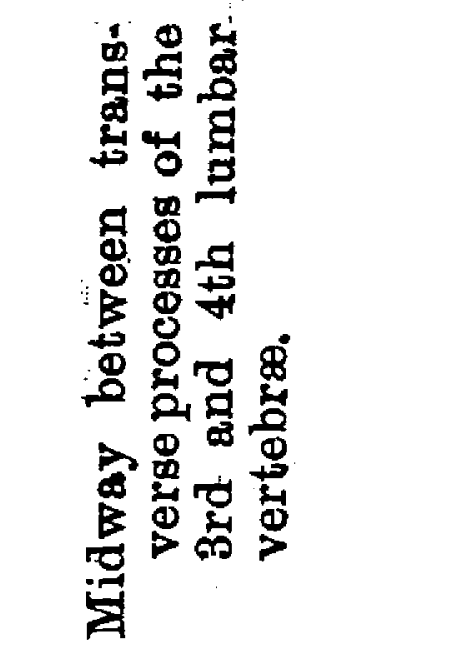 & 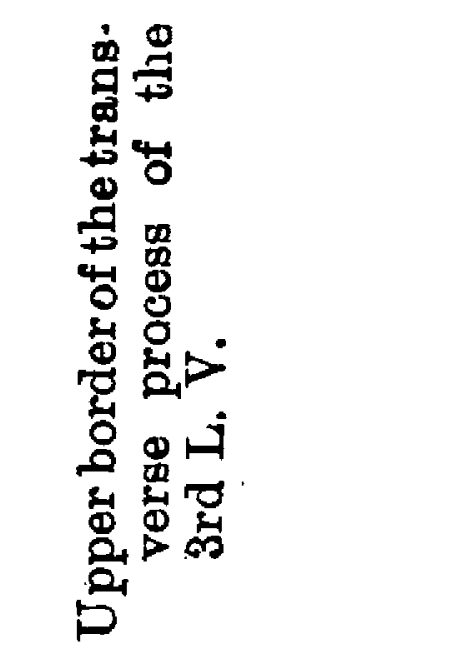 & 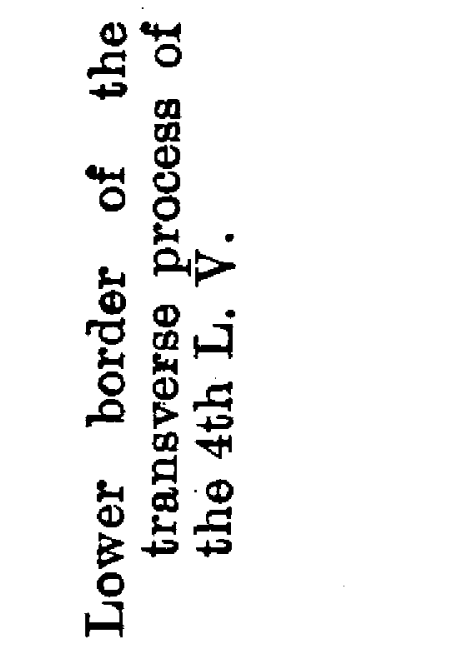 \\
\hline 익 & 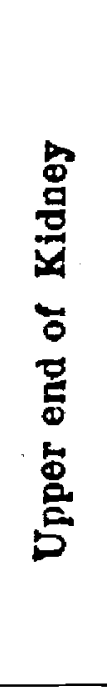 & 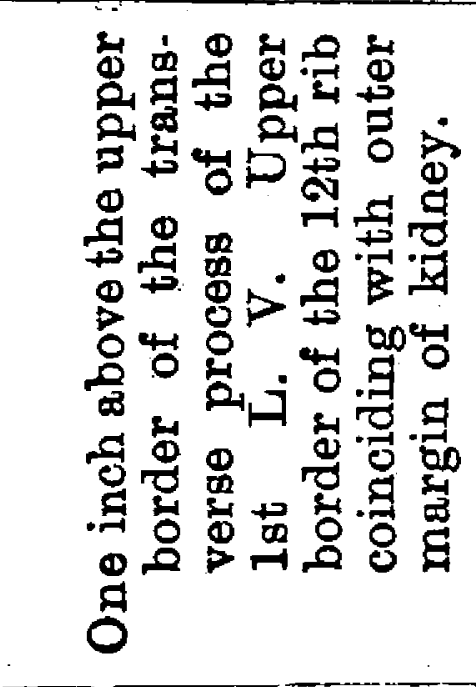 & 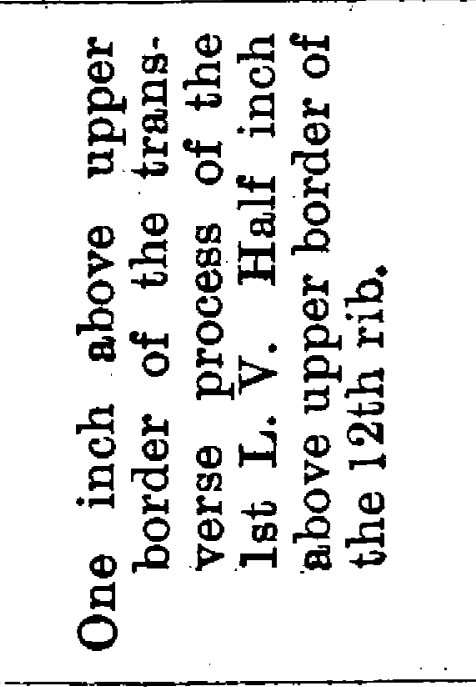 & 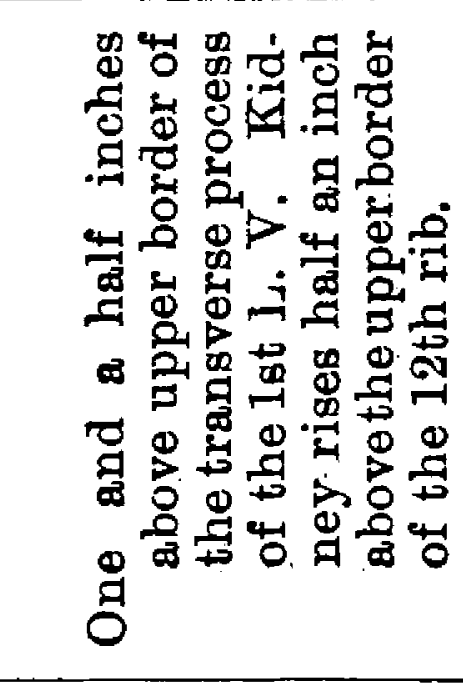 \\
\hline \multirow{2}{*}{$\overrightarrow{\underline{T}}$} & 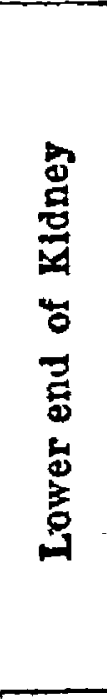 & 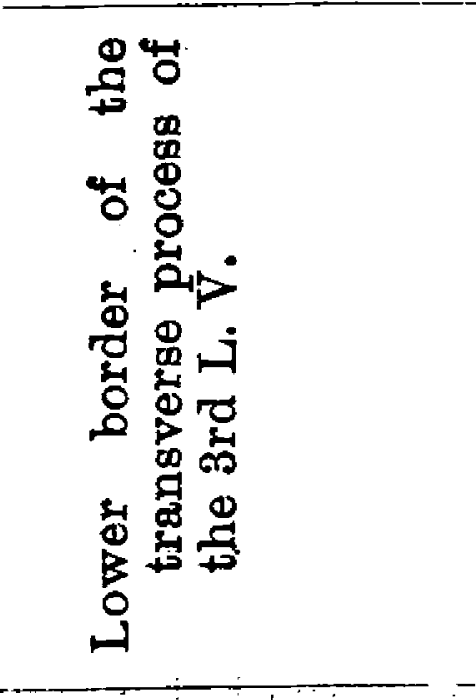 & 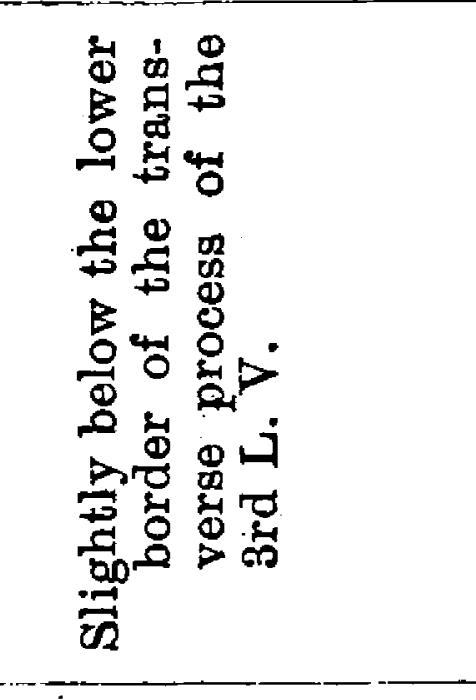 & 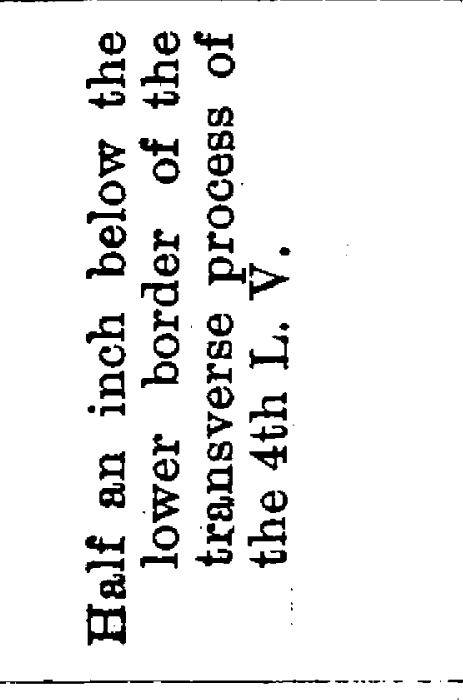 \\
\hline & 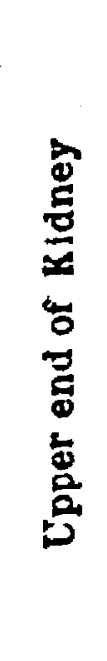 & 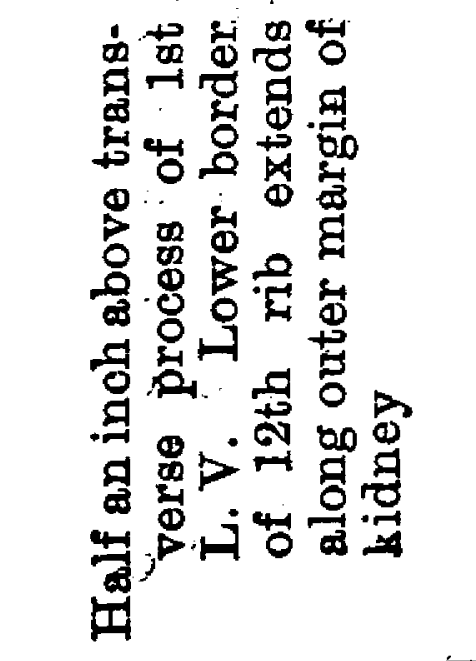 & 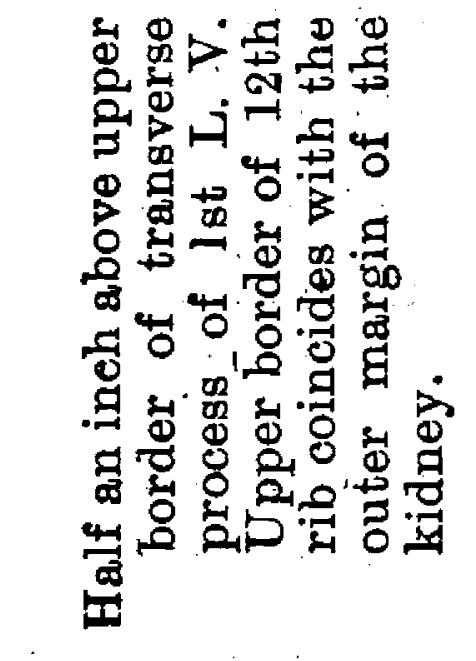 & 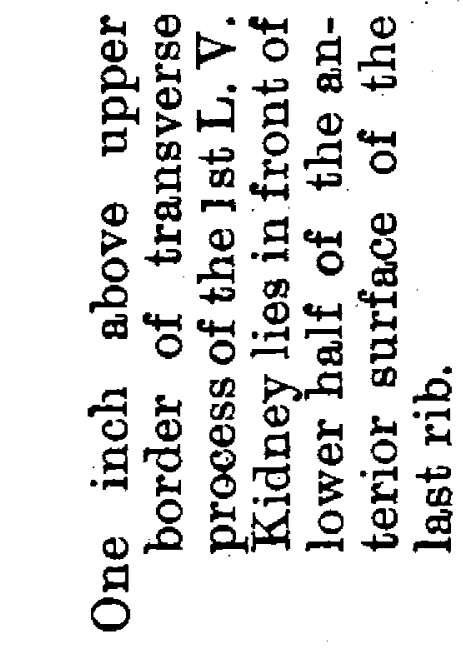 \\
\hline & 1 & 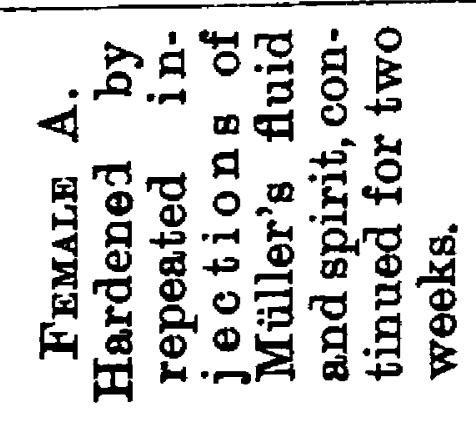 & 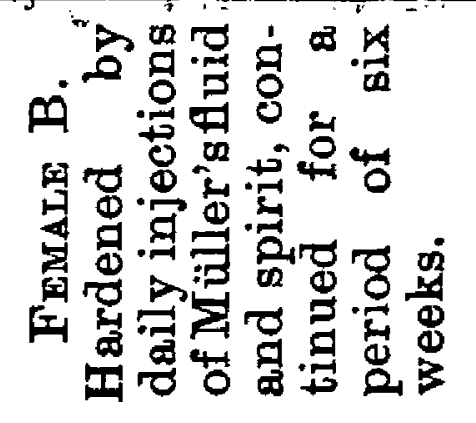 & 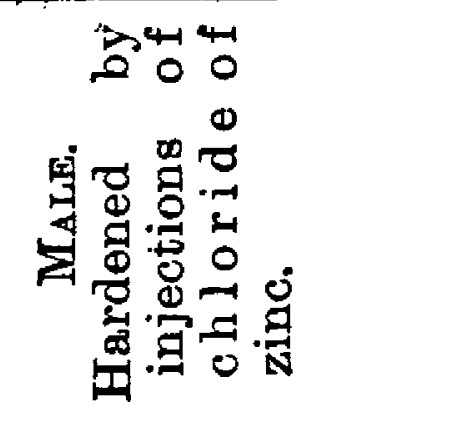 \\
\hline
\end{tabular}


By Dr. D. J. Cunningham.

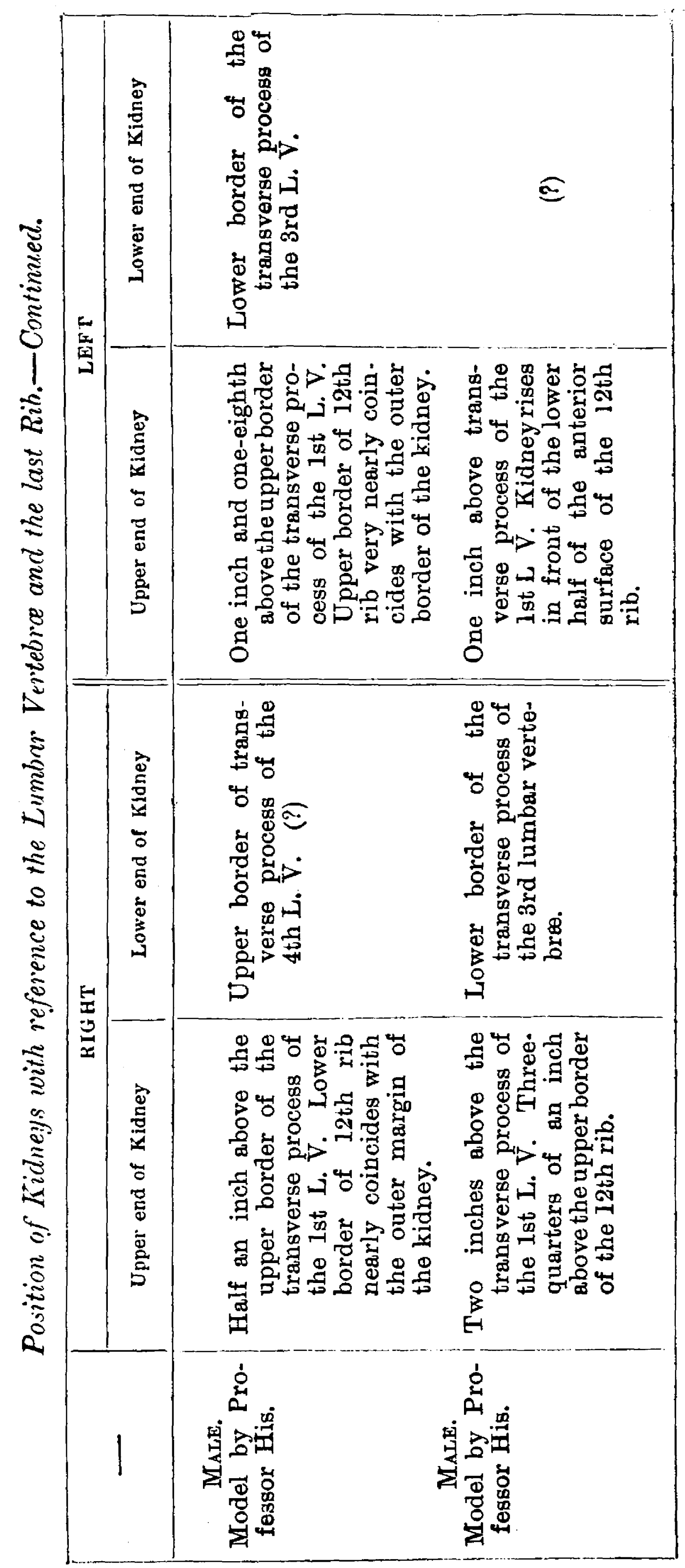


It will be noticed from the above table that the position of the kidney with reference to the vertebral column is much more constant than that which it presents to the 12 th rib. Further, the position of its upper extremity would seem to be subject to much less variation than that of its lower end. The posterior surface of the kidney exhibits two very distinct districts-viz., an internal and an external, which occupy different planes, and which meet along a vertical rounded border (Plate, Figs. 3 and 9). The internal district looks almost directly inwards and is moulded upon the psoas muscle and the crus of the diaphragm. It comprises those portions of the posterior surface which lie above and below the hilum. There is no demarcation of this district into a psoas and a diaphragmatic area. The part below the hilum and the posterior lip of the hilum, as a rule, rest upon the psoas. The internal arcuate ligament crosses the internal district immediately above the hilum, and the portion of this surface which lies above that line is in contact with the diaphragmatic crus.

The rounded ridge which separates the internal district on the posterior surface of the kidney from the external district takes a vertical direction, and corresponds in position to the outer margin of the psoas. In the upper part of the kidney, where the psoas gives place to the crus of the diaphragm, the ridge becomes rounded off, and the separation between the two districts becomes indistinct.

The external district on the posterior aspect of the kidney looks backwards, and is usually divided by an oblique furrow, placed near the upper end, and which proceeds in a downward and outward direction, into a small upper area and a larger lower area. The furrow is sometimes very strongly marked; at other times it is so shallow that it is hardly visible. It corresponds to the ligamentum arcuatum externum, and it is apt to be mistaken for a rib depression, seeing 
that it is not narrow in conformity with the tendinous cord which causes it, but broad and shallow. When this part of the posterior wall of the abdomen is examined in a wellhardened subject, the rounded elevation corresponding to the external arcuate ligament is clearly visible. In the subjects which $I$ have examined, this faint furrow or depression is much more distinctly marked on the right kidney than on the left; and this is, no doubt, due to the greater support which the left kidney receives from the last rib.

The portion of the external district which lies above the arcuate furrow rests on the diaphragm. This is of greater extent on the left kidney, and it is usually pressed to a greater or less degree forwards, in the manner described by Professor His. It is very imperfectly mapped off from the upper part of the internal district which rests on the diaphragmatic crus. The intervening ridge, as we have noted, becomes rounded off at this level.

The portion of the external district on the posterior surface of the kidney, below the external arcuate ligament, is moulded upon the quadratus lumborum muscle. It comprises much the larger part of this district, and is sharply marked off from the diaphragmatic area above and the psoas area internally.

But on a successfully hardened kilney certain skeletal markings may also be detected on the posterior surface. A narrow oblique impression, which corresponds with the 12 th rib, can generally be detected (Plate, Figs. 3 and 9 ). The position occupied by this differs in the two kidneys, and varies greatly in different individuals. But still further, in many cases the tips of certain of the transverse processes of the lumbar vertebræ produce corresponding dimples on the kidney immediately to the outer side of the ridge which separates the psoas imprint from the quadratus lumborum impression. In muscular and in obese subjects I question 
very much if any such depressions on the posterior surface of the kidney occur, but in the two female subjects which $I$ have prepared they are well marked in each of the four kidneys. In both kidneys taken from subject $A$ the tips of the 1st, 2nd, and 3rd transverse processes produce the dimples; in the case of subject $B$ the right kidney is marked by the tips of the 1st, 2nd, and 3rd transverse processes, whilst the left kidney is dimpled by the 2 nd and 3rd only.

Anyone who studies the changing forms of the viscera in the abdominal cavity cannot fail to observe the truth of Professor His's remarks regarding the part played by the hollow viscera in moulding the form of the solid organs. The hollow viscera are the active agents in this work, and the solid organs are as the passive clay in the hands of the modeller. Whether, under any circumstances, it is possible for a solid organ to impress a hollow viscus, such as the stomach, is a question which is difficult to answer. For my own part I am inclined to consider such a reaction impossible, or, at least, improbable. And this I say in direct opposition to the testimony afforded by my reconstructed model of the stomach. In this model the wall of the stomach where it is nipped between the liver and the spleen shows one or two wrinkles, and the projections on the notched border of the spleen are sunk into corresponding depressions in the stomach wall. This condition I am inclined to regard as being due to post-mortem relaxation of the coats of the stomach. That hollow viscera exercise a moulding influence on each other no one will question. The empty bladder is frequently impressed by the intestine which lies upon it, and, further, the coils of the small intestine, notwithstanding their constantly changing form, not only fit into each other with the greatest nicety, but also, to some extent, adjust their outlines to the opposing surfaces of the solid viscera. 
Irans.Roy.Acad.of.Med.Iretand, VoL.XIII.

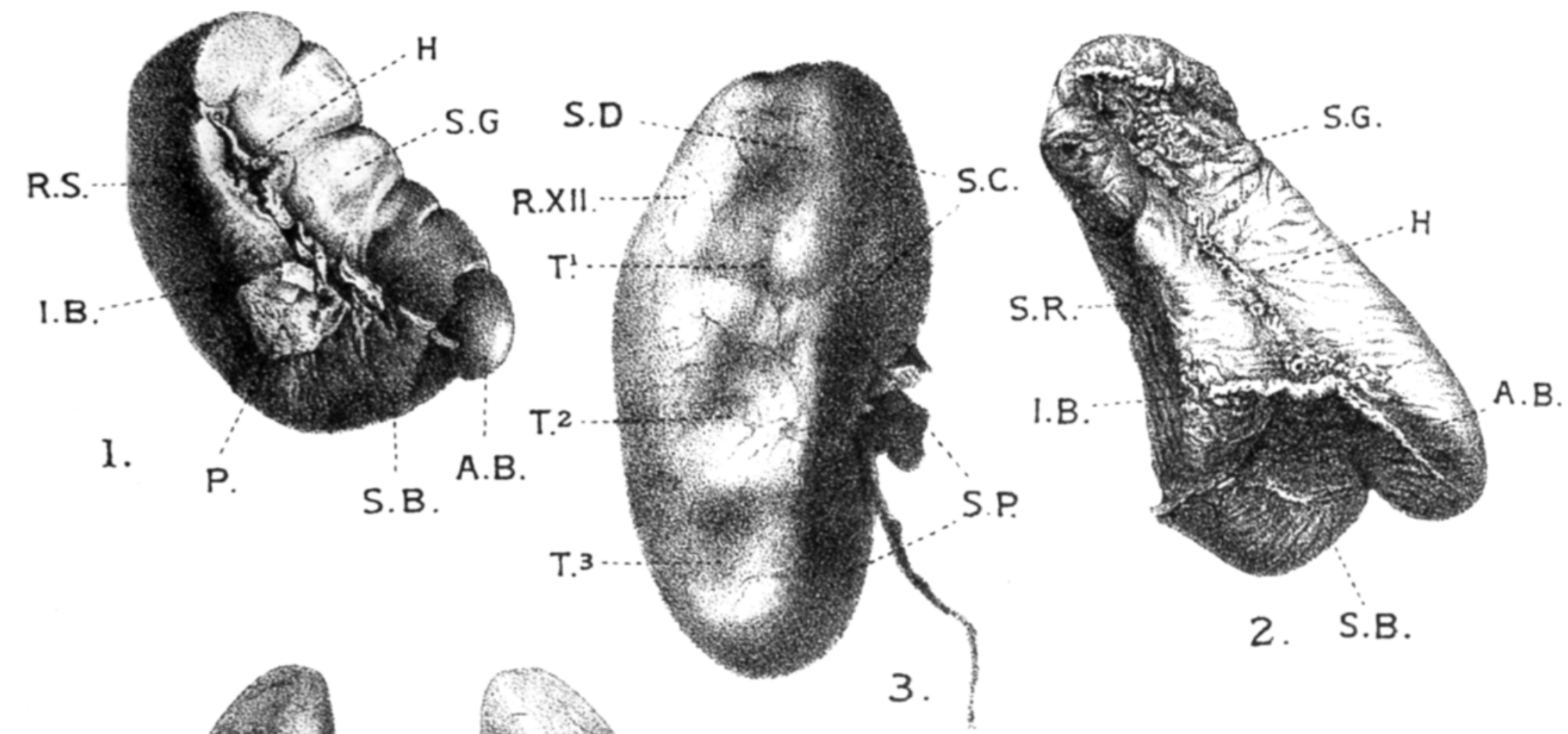

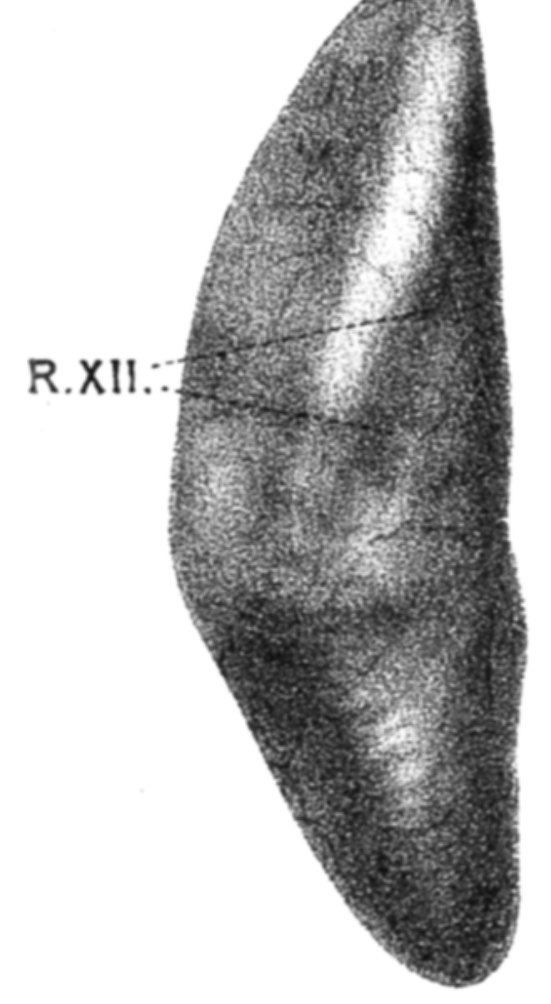

5.

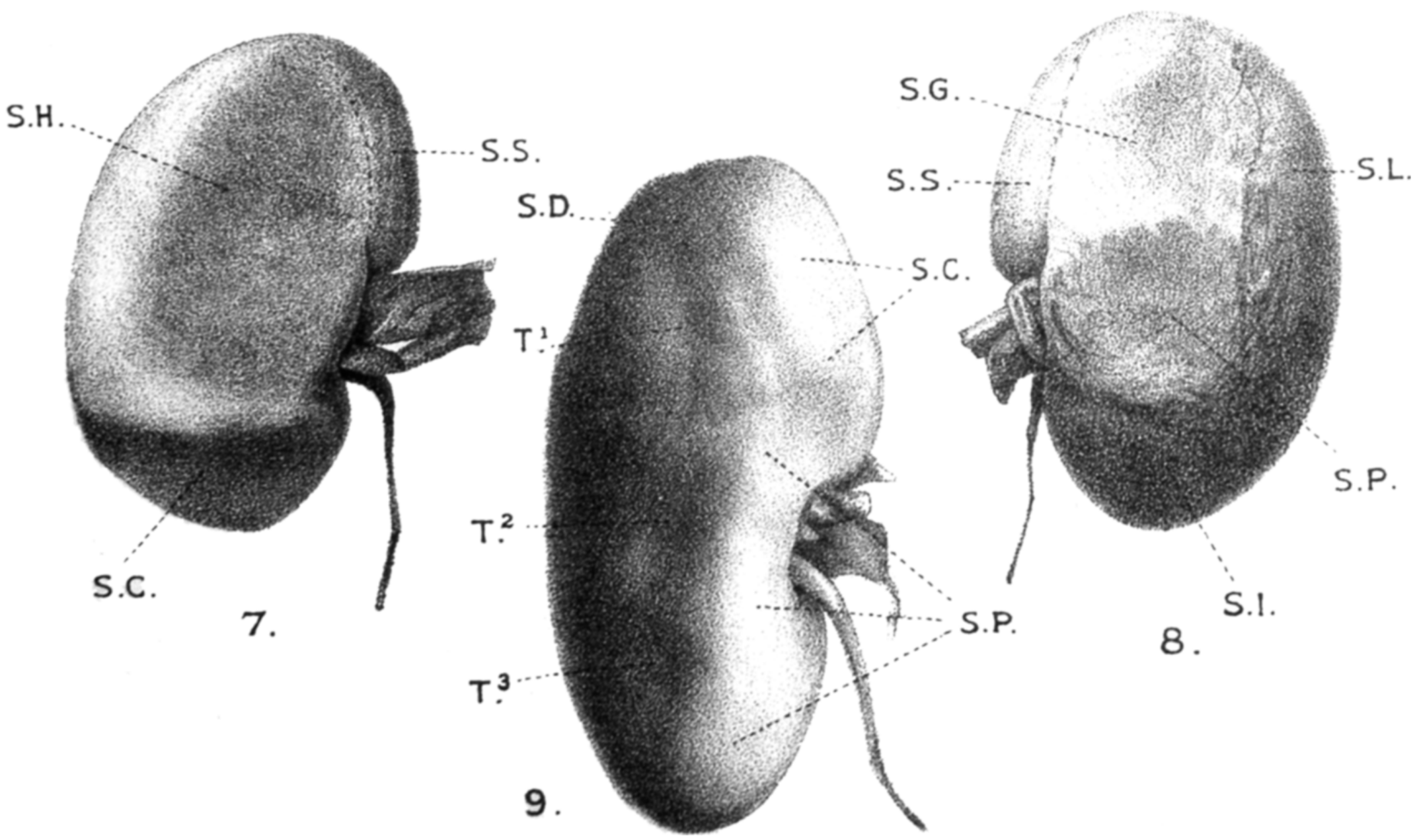

From Photo.

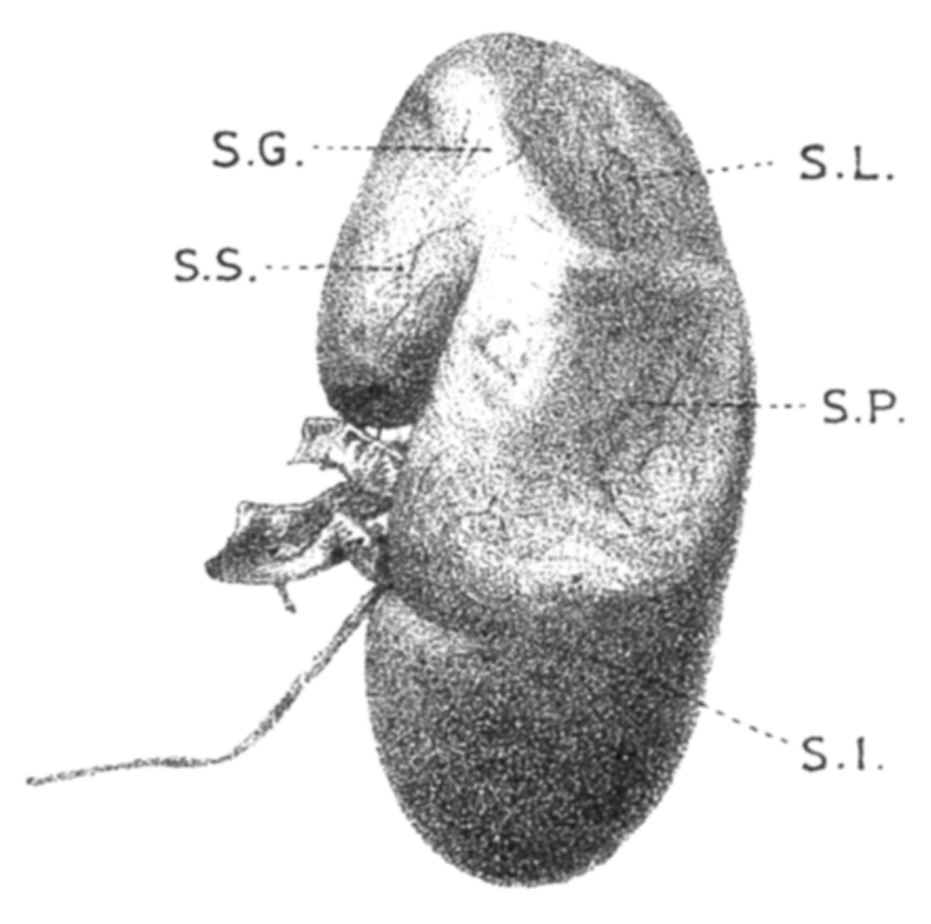

4.

$$
6 .
$$

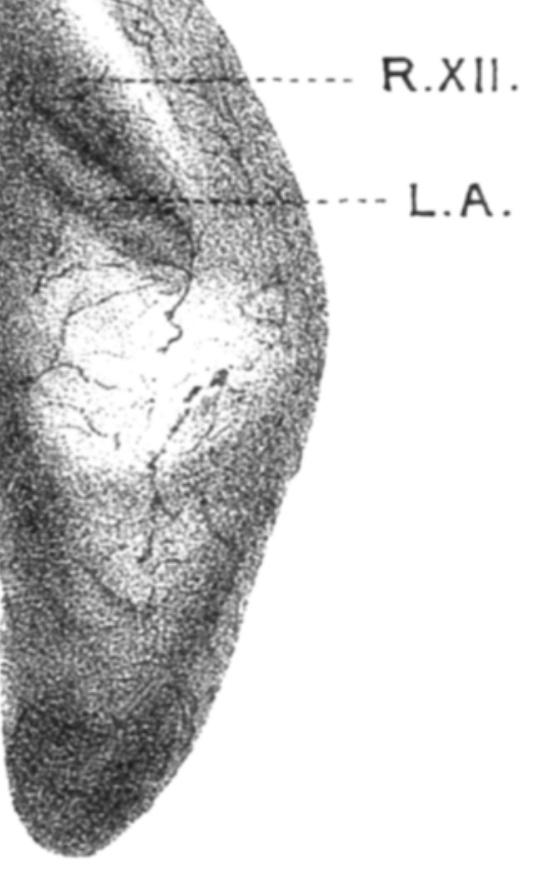

